\title{
Treatment of complicated spontaneous pneumothorax by simple talc pleurodesis under thoracoscopy and local anaesthesia
}

\author{
J M Tschopp, M Brutsche, J G Frey
}

\begin{abstract}
Background - Complicated (recurring or persistent) spontaneous pneumothorax requires treatment either by talc pleurodesis with bullae electrocoagulation or, more aggressively, by thoracotomy or video-assisted thoracoscopic surgery. However, the relative merits of bullectomy, pleurectomy, and pleurodesis have not yet been established in the treatment of spontaneous pneumothorax.

Methods - The complications, duration of drainage, length of hospital stay, and immediate and long term success rate of treating complicated spontaneous pneumothorax with talc pleurodesis under local anaesthesia supplemented with nitrous oxide were studied.

Results - Talc pleurodesis was performed in 93 patients without serious complication (two benign arrhythmias, two subcutaneous emphysema, two pneumonia, one bronchospasm). The procedure was immediately successful in 90 patients $(97 \%)$ with a median duration of drainage of five days (range 2-40) and a median length of hospital stay of 5.2 days (range 3-40). After a mean follow up duration of 5.1 (range 1-9.4) years in 84 cases the long term success rate was $95 \%$, although six cases developed a small localised recurrence of spontaneous pneumothorax which did not require further surgery. Macroscopic staging at thoracoscopy was only carried out in the last 59 cases of whom $10(17 \%)$ had bullae with a diameter of $>2 \mathbf{~ c m}$. In this group of patients the risk of definitive failure requiring surgery was significantly higher than in those patients without such bullae (odds ratio 7 ; confidence interval 3.7 to $13.3 ; p=0.03$ ), although eight of these patients did not require thoracotomy. Total lung capacity was reduced immediately after talc pleurodesis (mean (SD) 75 (23)\% predicted at 10 days) but had improved to 95 (14)\% predicted at 12 months.

Conclusions - This study shows that simple thoracoscopic talc pleurodesis under local anaesthesia is a safe and effective treatment for complicated spontaneous pneumothorax. However, patients with bullae of $>2 \mathrm{~cm}$ in diameter have a greater risk of treatment failure.

(Thorax 1997;52:329-332)
\end{abstract}

Keywords: complicated pneumothorax, video-assisted thoracoscopy, talc pleurodesis.
Spontaneous pneumothorax is a significant problem ${ }^{1}$ with an estimated recurrence rate of $23-50 \%$ after the first episode and higher after the first recurrence. ${ }^{2}$

There is little consensus about the treatment of spontaneous pneumothorax, with some authors $^{3}$ recommending treatment by thoracoscopy whereas others ${ }^{4}$ only recommend thoracoscopy for recurrent or complicated cases. Thoracotomy with pleurectomy and bullectomy is the definitive treatment for spontaneous pneumothorax and is associated with a very low recurrence rate but significant morbidity and mortality. ${ }^{5}$ There is also debate about whether the presence of bullae should alter the initial management. In patients with bullae of $>2 \mathrm{~cm}$ in diameter many authors recommend bullectomy either by thoracotomy or, more recently, by video-assisted thoracoscopic surgery and pleurectomy. ${ }^{78}$ However, both techniques require general anaesthesia and intubation with a double lumen tube. To avoid such invasive procedures it is generally accepted that, in the absence of bullae of $>2 \mathrm{~cm}$ diameter, chemical pleurodesis with talc by "medical" thoracoscopy - that is, with local anaesthesia - could be performed accompanied, if necessary, by electrocoagulation of bullous lesions. As others have observed, ${ }^{910}$ however, we are not aware of any controlled study showing that procedures such as pleurectomy, bullectomy, or leak sealing significantly decrease the incidence of recurrent spontaneous pneumothorax beyond the reduction that would result from performing pleurodesis by minimally invasive medical thoracoscopy.

In our hospital "medical" thoracoscopy has been carried out only for recurrent or persistent spontaneous pneumothorax, or for rare cases of a first episode of secondary spontaneous pneumothorax in patients with severe underlying lung disease, irrespective of the presence or absence of bullae. We now report the results of a study of the efficacy, complications, duration of drainage, and late recurrence rates of spontaneous pneumothorax treated only by talc pleurodesis under thoracoscopy and local anaesthesia. We have also investigated whether the presence of bullae with a diameter of $>2 \mathrm{~cm}$ is a risk factor for recurrence after talc pleurodesis by medical thoracoscopy.

Methods

THORACOSCOPY AND TALC PLEURODESIS

Patients were premedicated with atropine $0.5 \mathrm{mg}$ and during the procedure received 
titrated midazolam (3-10 $\mathrm{mg}$ ) and pethidine (25-100 mg) under careful supervision and continuous monitoring of blood pressure, ECG, oxygen saturation, and end tidal carbon dioxide pressure (Ohmeda, Louisville, USA).

Thoracoscopy was carried out in the lateral decubitus position under local anaesthesia with lignocaine $1 \%$. A $7 \mathrm{~mm}$ diameter trocar (Wolf, Knittlingen, Germany) was inserted in the fifth axillary intercostal space in the mid axillary line. A $0^{\circ}$ optical telescope (Panoview; Wolf) was inserted and connected to a video camera and monitor (Sony). The pleurae were inspected and any fluid was removed. By examining the chest radiographs and under direct vision we then selected the best site for the second point of entry. Two trocars and two chest tubes were used so that we could choose the best intercostal space to manipulate the lung with blunt forceps and inspect the visceral pleura in the apical and interlobar regions, cut any pleural adhesions by diathermy to expose all the visceral pleura to talc spraying, optimise talc spraying at the apex where lung lesions were generally found, and so that at the end of thoracoscopy we could leave one tube at the apex or adjacent to any bullae or pulmonary tears and one in the lower and posterior part of the pleural space to drain any pleural fluid. No electrocoagulation, stapling or ligation of any parenchymal lesions was carried out, even when a leak was visualised. At the end of the procedure the patient inhaled a mixture of $50 \%$ oxygen $/ 50 \%$ nitrous oxide and $3-5 \mathrm{ml}$ of pure talc was insufflated into the pleural space. The two drains (16 French gauge) were connected to underwater seal suction with a negative pressure of $30 \mathrm{~cm} \mathrm{H}_{2} \mathrm{O}$ for at least two days or until air leakage stopped. When an air leak persisted for more than seven days or a localised pneumothorax occurred, 500-1000 mg tetracycline chlorhydrate was instilled. If judged clinically necessary, a further thoracoscopic examination was performed with local application of talc if none was seen on the visualised pleura. Postoperative analgesia was carried out using $0.5-1 \mathrm{mg}$ intravenous morphine every 5-7 minutes self-administered by the patient (Lifecare PCA 4200 pump, Abbott Cham, Switzerland) in combination with intravenous propacetamol 1-6 g daily.

PATIENTS

Eighty nine patients of median age 30.5 years (range 15-79) referred to our chest hospital for persistent or recurrent spontaneous pneumothorax from 1986 to 1994 were included in the study. Persistent spontaneous pneumothorax was defined as a pneumothorax with persistent air leakage after seven days of chest tube drainage. Ninety three thoracoscopies with talc pleurodesis were performed in the 89 patients (bilateral talc pleurodesis in four cases), 78 of which were for recurrent spontaneous pneumothorax. Twenty eight cases had spontaneous pneumothorax associated with underlying lung disease (chronic obstructive pulmonary disease (COPD), previous tuberculosis, Marfan's syndrome, endometriosis, silicosis, AIDS with
Table 1 Thoracoscopic talc pleurodesis: complications and immediate success rate (93 procedures in 89 individuals)

Benign arrhythmia

Subcutaneous emphysema

Pneumonia

Bronchospasm

Pleurodesis in $<7$ days

Surgery in $<7$ days

Success with drainage $>7$ days

Successful second procedure

Unsuccessful second procedure

Immediate success rate

Total surgical cases (definitive failure)

Pneumocystis carinii pneumonia, sarcoidosis, bronchiectasis, or bullous lung disease without COPD). Seven had been refused general anaesthesia because of poor health.

In the last 59 cases who presented between 1990 and 1994 spontaneous pneumothorax was staged macroscopically according to Vanderschüren ${ }^{11}$ during thoracoscopy and they were followed up by lung function tests and chest radiography at six, 12 , and 24 months.

\section{DATA ANALYSIS}

Immediate success was defined as the proportion of cases with talc pleurodesis who had a complete re-expansion of their lung during the hospital stay, and long term success was defined as the number of cases with talc pleurodesis who did not require any surgical treatment at any time (first thoracoscopy or follow up). Results are expressed as mean (SD) with medians and ranges where relevant.

\section{Results}

MACROSCOPIC LESIONS

In the last 59 cases thoracoscopy showed a normal visceral pleura in 20 cases (stage I, $34 \%$ ) and some pleural adhesions in 11 cases (stage II, 19\%). One patient was in severe respiratory failure secondary to emphysema and talc was insufflated immediately without cutting any adhesions. Blebs or bullae with a diameter of $<2 \mathrm{~cm}$ were found in 18 cases (stage III, 30\%) and in 10 cases bullae with a diameter of $>2 \mathrm{~cm}$ (stage IV, 17\%) were found.

\section{IMMEDIATE SUCCESS RATE}

The median duration of drainage was five days (range 2-40) and the median length of hospital stay was 5.2 days (range 3-40). There were no serious complications such as empyema or reexpansion oedema and no deaths (table 1). One man with primary recurrent spontaneous pneumothorax required thoracotomy with pleurectomy after three days of drainage because of a large persistent air leak. Nine cases required a second procedure (details in table 2) with subsequent success in seven; three cases required a subsequent surgical procedure.

LONG TERM FOLLOW UP

Outpatient follow up information was obtained in $90 \%$ of cases for a mean of 5.1 (3.4) years. There were six late recurrences of spontaneous pneumothorax, two of which required no spe- 
Table 2 Thoracoscopic talc pleurodesis: details of second procedures and outcome of patients with spontaneous pneumothorax and drainage duration of $>7$ days

\begin{tabular}{|c|c|c|c|c|}
\hline $\begin{array}{l}\text { Patient } \\
\text { no./sex }\end{array}$ & $\begin{array}{l}\text { Age } \\
\text { (years) }\end{array}$ & Indication for talc pleurodesis & Second procedure & Outcome \\
\hline $1 / \mathrm{M}$ & 58 & Primary recurring SP & No lung re-expansion; thoracotomy at day 10 & Failure (surgery) \\
\hline $2 / \mathrm{M}$ & 73 & Secondary recurring SP with severe COPD & Persistent localised pneumothorax; 3rd drain & Success \\
\hline $3 / \mathrm{M}$ & 26 & Primary recurring SP & No lung re-expansion; tetracycline instillation & Success \\
\hline $4 / \mathrm{M}$ & 20 & Primary recurring SP & 3rd drain & Success \\
\hline $5 / \mathrm{F}$ & 20 & Primary recurring SP & Persistent localised pneumothorax; tetracycline instillation & Success \\
\hline $6 / M$ & 17 & Primary recurring SP & Bubbling; tetracycline instillation & Success \\
\hline $7 / \mathrm{F}$ & 30 & Primary recurring SP & Relapse after 3 days; new thoracoscopic TP & Success \\
\hline $8 / \mathrm{F}$ & 26 & Secondary bilateral SP with AIDS, PCP and ARDS & Bubbling ++ ; new thoracoscopic TP. Up to 5 drains on each side & Success \\
\hline $9 / \mathrm{M}$ & 36 & Primary recurring SP & No lung re-expansion; VATS at day 5 & Failure (surgery) \\
\hline
\end{tabular}

$\mathrm{SP}=$ spontaneous pneumothorax; $\mathrm{TP}=$ talc pleurodesis $\mathrm{COPD}=$ chronic obstructive pulmonary disease; VATS $=$ video-assisted thoracoscopic surgery; $\mathrm{PCP}=$ Pneumocystis carinii pneumonia; ARDS = adult respiratory distress syndrome.

cific treatment, three were treated definitively by a second thoracoscopic talc pleurodesis, and only one required thoracotomy.

At follow up at least one chest radiograph was obtained in 80 patients, of which seven showed minor obliteration of the lateral costophrenic angle. Repeated lung function tests were performed in 43 cases of whom 15 had suffered from chronic lung disease prior to talc pleurodesis. In this group some restrictive pattern of lung function was seen immediately after the procedure which gradually returned to normal in most of the patients, the total lung capacity being 75 (23), 91 (13), 95 (14) and $95(12) \%$ predicted at $0.3,6,12$, and 24 months, respectively.

In the last 59 patients who had macroscopic staging 10 had bullae of $>2 \mathrm{~cm}$ diameter (stage IV), four of whom relapsed and two proceeded to surgery (repeat pleurodesis or thoracotomy). In this group of patients the risk of definitive failure requiring surgery was significantly higher than in those patients without such bullae (odds ratio 7; confidence interval 3.7 to 13.3; $\mathrm{p}=0.03)$.

\section{Discussion}

The aim of treatment in patients with spontaneous pneumothorax is to achieve rapid reexpansion of the lung and permanent pleurodesis. We believe that we have obtained good results overall using simple talc pleurodesis by thoracoscopy with two drains, without resection or electrocoagulation. Our results support our hypothesis that successful treatment of complicated spontaneous pneumothorax requires adequate pleurodesis but that direct treatment of specific lesions such as ruptured bullae is not usually necessary. This makes the management of complicated spontaneous pneumothorax much simpler.

This study showed that patients with complicated spontaneous pneumothorax, and especially those with secondary pneumothorax complicated by respiratory insufficiency, can safely tolerate thoracoscopy with talc pleurodesis under local anaesthesia. This minimally invasive technique can be undertaken quickly (in approximately 15 minutes) by a well trained pulmonologist. The duration of drainage and length of hospital stay are comparable with other recent studies of the treatment of spontaneous pneumothorax either by "medical" talc pleurodesis, ${ }^{1213}$ thoracotomy, ${ }^{414-16}$ or video-as- sisted thoracoscopic surgery. ${ }^{6141517-21}$ We used talc as a sclerosing agent because it is inexpensive and has been shown experimentally to be more effective than tetracycline, laser coagulation, or electrocauterisation and is comparable in efficacy to surgical abrasion. ${ }^{22}$ Many clinical studies have confirmed its efficacy ${ }^{23}$ in comparison with tetracycline. ${ }^{1325}$ We used talc pleurodesis rather than slurry because of the higher incidence of side effects with the latter formulation. ${ }^{2627}$

At the beginning of the study, and because of the potential reported risks of talc slurry, we instilled tetracycline rather than repeating talc pleurodesis as a secondary procedure in the rare cases with localised persistent pneumothorax who required further treatment. However, we modified this approach after publication of a study ${ }^{28}$ which showed the innocuity of repeating localised talc pleurodesis. As recently reported, ${ }^{29}$ thoracoscopic talc pleurodesis is safe and effective in very large studies and mesothelioma has not been shown after talc pleurodesis even though talc has been in regular use in Europe since $1930 .{ }^{3031}$ We are not aware of complications in patients undergoing thoracic surgery or lung transplantation after a previous talc pleurodesis, although we would not recommend thoracoscopic talc pleurodesis in young patients who are potential candidates for lung transplantation. Pain related to talc pleurodesis was controlled by the combination of pethidine and midazolam, reinforced by inhalation of nitrous oxide which was safe, easy to use, and quickly reversible. We are not aware that other investigators have used nitrous oxide for thoracoscopic analgesia in spite of reports of its use without any complications in outpatients in the USA, ${ }^{32}$ and in the UK in conjunction with pethidine (Entonox) in many patients during labour.

Gillet-Juvin et $a l^{28}$ recently published results of the treatment of 71 cases of stage IV spontaneous pneumothorax with thoracoscopic talc pleurodesis and found a similar proportion (5\%) of patients requiring subsequent surgery. In our study two of 10 patients with stage IV pneumothorax required surgery before leaving hospital and two had a partial relapse at follow up that did not require any specific treatment. This suggests that patients with stage IV pneumothoraces are more at risk of definitive failure or partial relapse. It may therefore be that simple talc pleurodesis is not adequate in these patients. A recent study ${ }^{33}$ claimed to obtain 
good results after tetracycline pleurodesis. However, these authors excluded eight cases with persistent air leak from the analysis.

Overall, our findings support the use of thoracoscopic talc pleurodesis under local anaesthesia in the treatment of spontaneous pneumothorax. It provides a safe, cheap, and simple method of treatment for complicated pneumothorax.

1 Light RW. Management of spontaneous pneumothorax. Am Rev Respir Dis 1993;148:245-8.

2 Melton LJ, Hepper NGG, Offord KP. Incidence of spontaneous pneumothorax in Olomstedt

3 Boutin C, Viallat JR, Aelony Y. Practical thoracoscopy. Berlin: Springer Verlag, 1991.

4 Weeden D, Smith GH. Surgical experience in the management of spontaneous pneumothorax, 1972-82. Thorax 1983;38:737-43.

5 Krasnik M, Stimpel H, Halkier E. Treatment of primary spontaneous pneumothorax with intrapleural tetracycline instillation or thoracotomy. Follow-up of management program. Scand 7 Thorac

6 Janssen JP, Van Mourik J, Cuesta Valentin M, Sutedja G, Gigengack K, Postmus PE. Treatment of patients spontaneous pneumothorax during videothoracoscopy. Eur Respir F 1994;7:1281-4.

7 Inderbitzi R, Furrer M, Striffeler H, Althaus U. Thoracoscopic pleurectomy for treatment of complicated spontaneous pneumothorax. F Thorac Cardiovasc Surg 1993; 105:84-8.

8 Waller DA, Yoruk Y, Morritt GN, Forty J, Dark JH. Videothoracoscopy in the treatment of spontaneous pneumothorax:an int

9 Kirby TJ, RJ G. Management of pneumothorax and barotrauma. Clin Chest Med 1992;13:97-112.

10 Berger R. Editorial. Pleurodesis for spontaneous pneumothorax: will the procedure of choice please stand up? Chest thorax: will the proc

11 Vanderschueren RG. Le talcage pleural dans le pneumothorax spontané. Poumon-Coeur 1981;37:273-6.

12 Hausmann M, Keller R. Thorakoskopische Pleurodese beim Spontanpneumothorax. Schweiz Med Wochenschr 1994; 124:97-104

13 Almind M, Lange P, Viskum K. Spontaneous pneumothorax: comparison of simple drainage, talc pleurc and tetracycline pleurodesis. Thorax 1989;44:627-30.

14 Waller DA, Forty J, Morritt GN. Video-assisted thoracoscopic surgery versus thoracotomy for spontaneous pneumothorax. Ann Thorac Surg 1994;58:372-6.

15 Bernard A, Belichard C, Goudet P, Lombard JN, Viard H. Pneumothorax spontané. Comparaison de la thoraco- scopie et de la thoracotomie. Rev Mal Respir 1993;10 $433-6$.

16 Simansky DA, Yellin A. Pleural abrasion via axillary thoracotomy in the era of video-assisted thoracic surgery. Thorax 1994;49:922-3.

17 Inderbitzi R, Leiser A, Furrer M, Althaus U. Three years experience in video-assisted thoracic surgery (VATS) for spontaneous pneumothorax. I Thorac Cardiovasc Surg 1994;107:1410-5.

18 Khalife J, Avtan L, Feito B, Hureau J. Traitement des pneumothorax spontanés en vidéo-chirurgie: 32 observations. Chirurgie 1992;118:648-51.

19 Waller DA, Forty J, Soni AK, Conacher ID, Morritt GN. Videothoracoscopic operation for secondary spontaneous pict Ann Thorac Surg 1994;57:1612-5.

20 Yim AP, Ho JK, Lai CK, Chan HS. Primary spontaneous pneumothorax treated by video assisted thoracoscopic surgery: results of intermediate follow up. Aust NZ $7 \mathrm{Med}$ 1995;25:146-50.

21 Cole FH Jr, Cole FH, Khandekar A, Maxwell JM, Pate JW, Walker WA. Video-assisted thoracic surgery: primary therapy for spontaneous pneumothorax? Ann Thorac Sur 1995;60:931-3.

22 Bresticker MA, Oba J, LoCicero J, Greene R. Optimal pleurodesis: a comparison study. Ann Thorac Surg 1993; 55:364-7.

23 Viskum K, Lange P, Mortensen J. Long-term sequelae after talc pleurodesis for spontaneous pneumothorax. Pneumologie 1989;43:105-6.

24 Guérin JC, Champel F, Biron E, Kalb JC. Talcage pleural par thoracoscopie dans le traitement du pneumothorax. Rev Mal Respir 1985;2:25-9.

25 Boutin C, Rey F, Viallat JR. Etude randomisée de l'efficacite du talcage thoracoscopique et de l'instillation de tétracycline dans le traitement des pleurésies cancéreuses récidivantes. Rev Mal Respir 1985;2:374.

26 Sorensen PG, Svendsen TL. Treatment of malignant pleural effusion with drainage, with and without instillation of encir Dis 1984;65:131-5.

27 Rinaldo JE, Owens GR, Rogers RM. Adult respiratory distress syndrome following intrapleural instillation of talc. distress syndrome following intrapleural in

28 Gillet-Juvin K, Guérin JC. Le talcage sous thoracoscopie des pneumothorax par rupture de bulles d'emphysème. des pneumothorax par rupture de bulles d'emph

29 Aelony Y, Heffner JE, Rodriguez-Garcia JL. Thoracoscopic talc poudrage: comparison with tetracycline and use in Hodgkin's disease. Chest 1992;102:1922-3.

30 Bethune N. Pleural poudrage. A new technic for the deliberate production of pleural adhesions as a preliminary to lobectomy. F Thorac Cardiovasc Surg 1935;4:251-61.

31 Research Committee of the British Thoracic Association and the Medical Research Council Pneumoconiosis Unit. A survey of the long-term effects of talc and kaolin pleurodesis. Br f Dis Chest 1979;73:285-8.

32 Stach D-J. Nitrous oxide sedation: understanding the benefits and risks. Am f Dent 1995;8:47-50.

33 Alfageme I, Moreno L, Huertas CVA, Hernandez J, Betzegu A. Spontaneous pneumothorax. Long-term results with tetracycline pleurodesis. Chest 1994;106:347-50. 